\section{ASSESSING CARDIAC OUTPUT AND DERIVED BLOOD VOLUMES IN A NEONATAL LAMB MODEL WITH A LEFT-TO-RIGHT SHUNT}

S.L. Vrancken ${ }^{1}$, W.-P. de Boode ${ }^{1}$, J.C. Hopman², S.K. Singh ${ }^{3}$, K.D. Liem ${ }^{1}$

${ }^{1}$ Department of Neonatology, ${ }^{2}$ Laboratory of Clinical Physics, ${ }^{3}$ Department of Pediatric Cardiothoracic Surgery, Radboud University Nijmegen Medical Centre, Nijmegen, The Netherlands

Aims: To assess cardiac output and derived blood volumes in lambs with a left-to-right shunt using the ultrasound dilution technique (UDCO).

Methods: In 8 lambs (mean weight $6.4 \mathrm{~kg}$ ) arterial and central venous catheters were inserted and connected to the UDCO-monitor (COstatus ${ }^{\mathrm{TM}}$ ). A Gore-Tex ${ }^{\circledR}$ shunt was placed between the left pulmonary artery and the descending aorta. This shunt was intermittently opened and closed while cardiac output was changed by creating hemorrhagic hypotension followed by fluid administration (closed shunt only). Measurements of cardiac output ( $\mathrm{Q}^{\mathrm{UDCO}}$ ), central blood volume index (CBVI), active circulating volume index $(\mathrm{ACVI})$ and total enddiastolic volume index (TEDVI) were performed using the UDCO.

Results: 342 measurements were performed. Mean cardiac output was $160 \mathrm{~mL} / \mathrm{kg} / \mathrm{min}$. Mean $\mathrm{Qp} / \mathrm{Qs}$ ratio during open shunt was 1.7. Mean total hemorrhage was $17.8 \mathrm{~mL} / \mathrm{kg}$ and mean total fluid administration $28.5 \mathrm{~mL} / \mathrm{kg}$. Figures 1 shows mean values of $\mathrm{Q}^{\mathrm{UDCO}}, \mathrm{CBVI}, \mathrm{ACVI}$ and TEDVI during the entire experiment. During shunt opening, only changes in TEDVI were significant $(p=0.038)$. During hemorrhage, CBVI and TEDVI decreased significantly with closed and open shunt (CBVI: $p<$ 0.001 respectively $p<0.001$ and TEDVI: $p<0.001$ respectively $p=0.027$ ), while $Q^{\mathrm{UDCO}}$ only decreased significantly with closed shunt $(p=0.03)$. There were no significant ACVI changes, probably due to redistribution. During fluid administration, $\mathrm{Q}^{\mathrm{UDCO}}$ and all volumes increased significantly.

Conclusion: The expected changes in cardiac output and derived blood volumes can be detected with UDCO technology, even in the presense of leftto-right shunts.

\section{Cardiac output and derived blood volumes}

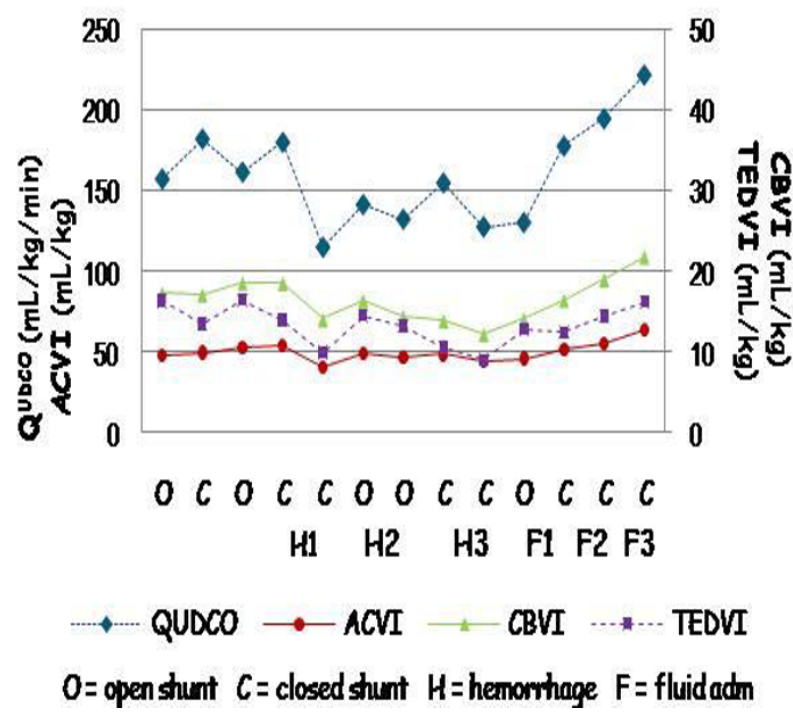

[cardiac output and derived volumes]

\section{1}

IMPACT OF BALLOON ATRIAL SEPTOSTOMY ON CEREBRAL OXYGEN SATURATION AND OXYGEN EXTRACTION IN NEONATES WITH TRANSPOSITION OF THE GREAT ARTERIES

\author{
M.E. van der Laan ${ }^{1}$, E.A. Verhagen', \\ E.M.W. Kooi ${ }^{1}$, R.M.F. Berger ${ }^{2}$, A.F. Bos ${ }^{1}$
}

${ }^{1}$ Divison of Neonatology, ${ }^{2}$ Division of Pediatric Cardiology, Beatrix Children's Hospital, University Medical Center Groningen, Groningen, The Netherlands

Background: Neonates with transposition of the great arteries (TGA) are at risk of hypoxicischemic brain-injury. Balloon atrial septostomy (BAS) improves mixing of oxygen-saturated and -desaturated blood. We determined the impact of BAS on regional cerebral tissue oxygen saturation $\left(\mathrm{r}_{\mathrm{c}} \mathrm{SO}_{2}\right)$ and fractional cerebral tissue oxygen extraction (FTOE) in neonates with TGA.

Methods: Term neonates with TGA were included. $\mathrm{R}_{\mathrm{c}} \mathrm{SO}_{2}$ was measured with nearinfrared spectroscopy 2 hours (hrs) before, $2 \mathrm{hrs}$ after, and $24 \mathrm{hrs}$ after BAS for a two-hour period. Transcutaneous arterial oxygen saturation $\left(\mathrm{tcSaO}_{2}\right)$ was measured simultaneously. FTOE was calculated: $\mathrm{FTOE}=\left(\mathrm{tcSaO}_{2}-\mathrm{r}_{\mathrm{c}} \mathrm{SO}_{2}\right) / \mathrm{tcSaO}_{2}$. In neonates who did not need BAS on clinical grounds, according to the attending cardiologist, $\mathrm{tcSaO}_{2}$ and $\mathrm{r}_{\mathrm{c}} \mathrm{SO}_{2}$ were measured twice for a two-hour period: once within $24 \mathrm{hrs}$ after admission and once $24 \mathrm{hrs}$ 
later. Data were analysed by multi-level analysis and Mann-Whitney-U-test.

Results: Nine neonates (median age: 1 day [range:0-18]) underwent BAS and four neonates (median age: 4 days [range:0-6]) did not. $\mathrm{R}_{\mathrm{c}} \mathrm{SO}_{2}$ increased after BAS (from mean $37 \%$ to $49 \%$ to $64 \%[\mathrm{p}=0.000]$ ), as did $\mathrm{tcSaO}$ (from mean $68 \%$ to $81 \%$ to $84 \%$ [p=0.000]). FTOE decreased after BAS (from mean 0.46 to 0.40 to 0.25 [p=0.000]). Neonates who did not need BAS showed higher

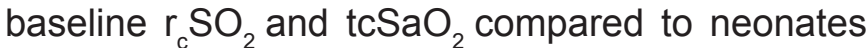
who did (median $57 \%$ vs $35 \%$ [ $p=0.020$ ] and $88 \%$ vs $77 \%$ [ $p=0.034]$, respectively). After BAS, there were no differences between both groups.

Conclusion: In neonates with TGA in need of BAS, $\mathrm{r}_{\mathrm{c}} \mathrm{SO}_{2}$ increased and FTOE decreased following BAS. This suggests improved cerebral oxygenation, which, possibly, protects against hypoxic-ischemic brain-injury.

\section{2}

\section{SECOND COURSE OF IBUPROFEN FOR PDA : COMPARISON OF 10-5-5 VS 20-10-10 MG/KG IN INBORN INFANTS $<28$ WKS GA}

\author{
X. Durrmeyer, E. Millot, F. Decobert, C. Danan, \\ I. Layouni, G. Dassieu \\ Réanimation Néonatale, Centre Hospitalier \\ Intercommunal de Créteil, Créteil, France
}

Background and aims: Recent pharmacological data suggest increased ibuprofen doses for treating patent ductus arteriosus (PDA). We evaluated the effectiveness and tolerance of a double dosed second ibuprofen course in our population.

Methods: In our unit PDA management relies on systematic and repeated echocardiographic exams seeking strict treatment criteria (ductal diameter, left atrium/aortic root, left pulmonary artery diastolic blood flow). Persistent echocardiographic criteria after a first ibuprofen course induce a second course if not contra-indicated.

We conducted a monocenter retrospective study by comparing two time periods: November 2004 to March 2006 and April 2006 to November 2009 where the second ibuprofen course doses respectively were 10-5-5 (IBU1) and 20-10-10 (IBU2) mg/kg. Baseline characteristics, treatment incidence, ductal closure and complications were compared between IBU1 and IBU2. Term-based subgroup analysis was performed ( $<$ or $\geq 26$ wks GA).
Results: IBU1 and IBU2 populations were comparable. Ductal closure was more frequent for IBU2 $(23 / 55,42 \%)$ than for IBU1 $(3 / 23,13 \%)$ $(p=0,02)$. Subgroup analysis confirmed this result only for infants $\geq 26$ wks $G A$.

Incidence of mortality and common morbidities were comparable between IBU1 and IBU2. Among infants $<26$ wks GA we observed a higher, although not significant, incidence of "death or BPD" for IBU2 vs IBU1 (37\% vs 9\%).

Conclusions: This is the largest report of increased ibuprofen doses in infants < 28 wks GA with systematic echocardiographic assessment. In this study risk/benefit balance supports the use of a double-dosed second course of ibuprofen for PDA treatment only in infants $\geq 26$ wks GA.

\section{3}

\section{THE DEFINITION OF A HEMODYNAMIC SIGNIFICANT DUCT IN RANDOMISED CONTROLLED TRIALS, A SYSTEMATIC LITERATURE REVIEW}

\section{Zonnenberg ${ }^{1}$, K. de Waal ${ }^{2}$}

${ }^{1}$ Neonatology, VU Medical Centre, Amsterdam, The Netherlands, ${ }^{2}$ Neonatology, John Hunter Hospital, Newcastle, NSW, Australia

The ductus arteriosus is associated with morbidity in preterm infants. Treatment is prescribed for a hemodynamically significant duct (HSDA), but its definition varies. We systematically reviewed published clinical and ultrasound definitions (US) of a HSDA.

Methods: Pubmed and the Cochrane library were searched for randomised trials on ductal closure or trials evaluating the prevention of a symptomatic duct developing.

Results: Fifty nine trials were included in our review. Thirty nine trials used clinical and US criteria to define a HSDA, 5 trials clinical criteria only, 10 trials US criteria only, 2 trials clinical or US criteria and in 3 trials the criteria were not mentioned. Re-entry criteria for ductal assessment was clinical only (2), clinical followed by ultrasound (39), US only (3) or it was not mentioned (15). Clinical criteria were defined in 41 trials, with murmur (29), bounding pulses (27), hyperdynamic precordium (24), cardiomegaly (19) and respiratory status (19) most reported on. US criteria were defined in 50 trials, with LA/Ao ratio $>1.15$ to 1.7 being most reported (33). Other US 